University of Nebraska - Lincoln

DigitalCommons@University of Nebraska - Lincoln

Other Publications in Zoonotics and Wildlife

Disease

Wildlife Disease and Zoonotics

1990

\title{
Determining Matrilines by Antibody Response to Exotic Antigens
}

Gregory E. Glass

Johns Hopkins University

James E. Childs

Johns Hopkins University, james.childs@yale.edu

James W. LeDuc

Institute of Infectious Diseases, Frederick

Sandra D. Cassard

The Johns Hopkins Oncology Center, Baltimore

Albert D. Donnenberg

Johns Hopkins University

Follow this and additional works at: https://digitalcommons.unl.edu/zoonoticspub

Part of the Veterinary Infectious Diseases Commons

Glass, Gregory E.; Childs, James E.; LeDuc, James W.; Cassard, Sandra D.; and Donnenberg, Albert D., "Determining Matrilines by Antibody Response to Exotic Antigens" (1990). Other Publications in Zoonotics and Wildlife Disease. 81.

https://digitalcommons.unl.edu/zoonoticspub/81

This Article is brought to you for free and open access by the Wildlife Disease and Zoonotics at DigitalCommons@University of Nebraska - Lincoln. It has been accepted for inclusion in Other Publications in Zoonotics and Wildlife Disease by an authorized administrator of DigitalCommons@University of Nebraska - Lincoln. 


\title{
J OURNAL OF MAMMALOGY
}

\author{
Published Quarterly by the American Society of Mammalogists
}

\begin{tabular}{lll}
\hline VOL. 71 & 21 MAY 1990 & No. 2 \\
\hline
\end{tabular}

\section{DETERMINING MATRILINES BY ANTIBODY RESPONSE TO EXOTIC ANTIGENS}

\author{
Gregory E. Glass, James E. Childs, James W. LeDuc, \\ Sandra D. Cassard, and Albert D. Donnenberg \\ Department of Immunology and Infectious Diseases, School of Hygiene and Public Health, \\ Johns Hopkins University, 615 North Wolfe Street, Baltimore, MD 21205 (GEG, JEC, ADD) \\ Department of Epidemiology, U.S. Army Medical Research \\ Institute of Infectious Diseases, Frederick, MD 21701 (JWL) \\ The Johns Hopkins Oncology Center, Baltimore, MD 21205 (SDC, ADD) \\ Present address of SDC: Department of Health Policy and Management, \\ School of Hygiene and Public Health, 600 North Broadway Street, Baltimore, MD 21205 \\ ABstract-D - The antibody responses of female Microtus pennsylvanicus inoculated with a series \\ of antigens not normally encountered under field conditions were examined, and the kinetics of \\ maternally acquired antibody loss in their offspring were determined. The initial antibody response \\ in adults was rapid, peaking in 4-9 weeks, and long-lasting, with a half life of 4-5 months. \\ Antibody levels in females were unaffected by parity, and more than one antigen could be given \\ without affecting circulating-antibody titers. Antibody titers could be enhanced with additional \\ inoculations. Maternal antibody in offspring increased until weaning at 3 weeks then declined \\ exponentially. Minimal detectable titers were reached at 7-11 weeks. In many instances, maternal \\ antibody remained detectable even after offspring reached adult $(35 \mathrm{~g})$ size. Examination of \\ uninoculated wild-caught voles showed only one of 130 tests produced a "false" positive response. \\ The exotic-antigen technique may be generally applicable for determining maternity in small, \\ secretive mammals.
}

Many current theories in population biology and genetics have at their foundations the relatedness, and the relative reproductive success of population members (Komnicki, 1988; Mangel and Clark, 1988). Some of these theories were addressed in detailed studies of large mammals (LeBoeuf and Reiter, 1988; Packer et al., 1988), but the low population densities, long generation time, and vagility of these species make their use expensive, labor intensive, and of extremely long duration. In addition, populations of large mammals rarely are amenable to experimental manipulations. These difficulties are not associated with studies of small mammals, but the young usually are sampled only after they have terminated contact with their mothers. As a consequence, maternal-offspring relationships often are impossible to determine.

A variety of techniques have been used to associate females and their offspring in the field; nest boxes (Goundie and Vessey, 1986; Smith and Sloan, 1988), trapping patterns (Beacham, 1979), sampling at burrow entrances (Jones, 1987), and patterns of allozymic variation (Chesser, 1983) have been tried but none is generally applicable. Rongstad (1965), and Wolff and Holleman (1978) showed that female rodents injected with radioactive isotopes passed them to their infants during nursing. Tamarin et al. (1983) identified offspring by the characteristic spectrographic pattern associated with the decay of several different radionuclides. Scott and Tan (1985), Sheridan and Tamarin (1986), and Tamarin et al. (1983) used this technique to identify suc- 
cessfully the relative reproductive success of free-ranging Antechinus stuartii and Microtus pennsylvanicus. However, these workers reported that injected animals excrete radionuclides into the environment, raising potential problems with state and federal regulatory statutes concerning the disposal of radioactive materials (R. H. Tamarin, pers. comm.). Also, animals must be placed in a whole-body counter for 1.5-6 min. Time constraints could occur if large numbers of animals must be processed as all new animals must be examined before release. Additionally, females often eliminate most of their radionuclide burden by the end of weaning necessitating booster doses after each litter is born to make offspring identification unequivocal (Tamarin et al., 1983). Sampling-induced trap shyness may make it difficult to provide booster doses. Finally, it is not possible to mark both males and females with isotopes in the same study, as spectrographic patterns may overlap. Consequently, two separate methods are required; one to establish paternity, the other to determine maternity. If an alternative method could be developed to establish maternity then radionuclide marking could be used to establish mating success of males (Scott and Tan, 1985).

An alternative method for marking offspring could take advantage of the humoral immune response of mammals whereby individuals exposed to an antigen react by producing antibodies specifically directed against the antigen (Klein, 1982). Immunoglobulins in pregnant and lactating females are transmitted to their offspring across their placentae and during nursing, providing the mechanism for passive immunization of infants by maternally derived antibodies (Brambell, 1970). By this process, we proposed to determine maternal-offspring relationships by immunizing females against antigens not encountered in the natural environment (exotic antigens), and measuring antibody profiles in their offspring.

Herein, we outline laboratory studies of antibody responses to exotic antigens in breeding female M. pennsylvanicus, and report on the kinetics of maternal antibody loss in their offspring. Our goals were to examine the duration of antibody responses in mothers, the effects of multiple litters on their antibody responses, the possibility of increasing the antibody responses by providing boosters of antigens, the effect of immunizations with multiple antigens on antibody responses, the ability of the assay systems to detect differential responses to different but similar antigens, and the frequency of uninoculated wild voles with antibodies to these or related antigens.

\section{Materials AND Methods}

Female M. pennsylvanicus were obtained from a breeding colony at the U.S. Army Medical Research Institute of Infectious Diseases, Frederick, Maryland. Twelve- to 24-week-old females were inoculated subcutaneously at two to four sites in their flanks with $200 \mu \mathrm{l}$ of antigen-adjuvant mixture. Antigens were used at a concentration of $1 \mathrm{mg} / \mathrm{ml}$ dissolved in sterile saline and mixed with equal volumes of complete Freund's adjuvant. Females were inoculated with either tetanus toxoid, diphtheria toxoid, bovine thyroglobulin, porcine thyroglobulin, or keyhole limpet (Megathura crenulata) hemocyanin as antigens. Antigens were obtained from commercial sources. Four to eight females were assigned to each group. Three females were inoculated with complete Freund's adjuvant alone, as negative controls.

To examine the effect of multiple antigens on the primary immune response, seven females were inoculated with diphtheria and tetanus toxoids, simultaneously. After 3 (diphtheria-tetanus) or 6 (tetanus) months half of the females in the tetanus toxoid and the diphtheria-tetanus groups received a second (booster) immunization with $100 \mu \mathrm{l}$ of the appropriate antigens in sterile saline. Freund's adjuvant was not used during these inoculations.

One week after inoculations, females were paired individually with males. Cages were examined 17. days later and daily, thereafter, for offspring. The date of birth was noted for each litter. Body weights for most offspring were recorded to the nearest $0.5 \mathrm{~g}$ beginning at 2 weeks of age, and at biweekly intervals thereafter.

The presence of circulating immunoglobulin-G antibodies was determined from serum samples. Females were bled $(100 \mu \mathrm{l})$ from their infraorbital sinuses, by capillary tube, before inoculation and at biweekly intervals unless newborn offspring were present. Offspring were bled, with their mothers, at 2 weeks of age. Blood samples were centrifuged, the sera collected, and stored at $-20^{\circ} \mathrm{C}$ until tested.

Antibody titers were determined by indirect enzyme-linked immunosorbent assays optimized for each antigen (Drummond et al., 1985; Voller and Bidwell, 1986). Antigens $(2 \mu \mathrm{g} / \mathrm{ml})$ dissolved in a carbonatebicarbonate buffer $\left(\mathrm{pH}=9.6\right.$ ), were coated onto 96 -well microtiter plates by incubating overnight at $4^{\circ} \mathrm{C}$. 
Plates were stored for $\leq 2$ weeks under these conditions. Before use they were washed in phosphate buffered saline. Empty binding sites were blocked by incubation with $5 \%$ bovine serum albumin in phosphate buffered saline at $37^{\circ} \mathrm{C}$ for $1 \mathrm{~h}$. Two microliters of vole sera were diluted $1: 100$ in $1 \%$ bovine serum albumin and phosphate buffered saline, added to each plate, and serially diluted in two-fold steps to 1:12,800. Plates were incubated at $37^{\circ} \mathrm{C}$ for $1 \mathrm{~h}$, washed, and $100 \mu \mathrm{l}$ of alkaline phosphatase-conjugated goat antimouse immunoglobulin-G (1:250 in phosphate buffered saline) added. Plates were incubated for $2 \mathrm{~h}$ at $37^{\circ} \mathrm{C}$, washed and incubated with $p$-nitrophenyl phosphate $(0.5 \mathrm{mg} / \mathrm{ml})$ dissolved in diethanolamine for $0.5 \mathrm{~h}$ at room temperature to visualize the reaction. Reactions were stopped by adding $50 \mu \mathrm{l}$ of $3 \mathrm{M} \mathrm{NaOH}$. Endpoint titers were determined by measuring optical densities of test reactions in a spectrophotometer, and fitting a polynomial curve to the graph of the optical densities as functions of dilutions. Antibody titers of sera were defined as the inverse of the dilutions $\geq 3 S D$ above the value of the negative control serum.

Kinetics of primary antibody responses were described by graphing the average titer $\pm 95 \%$ confidence intervals against time for each experimental group. Dynamics of maternal-antibody loss in offspring of inoculated females were determined by regressing the average logarithm (base 2) of the titer against time. Antibody profiles generally follow an exponential decay over time (Brambell, 1970). Thus, the expected fit was a straight line with a negative slope, where the $x$-intercept defined the expected time that detectable maternal antibody disappeared from the circulations of the offspring. The specificity of the antibody responses was examined by comparing antibody titers of animals inoculated with porcine or bovine thyroglobulins against the heterologous antigens.

Sera from 26 wild-caught voles (Childs et al., 1987) were screened at 1:100 dilutions against each antigen to determine if naive wild animals have antibodies to these or other cross-reacting antigens. Sera with optical densities $>3 S D$ units above the mean of three negative control sera, included on each plate, were titrated to endpoint.

\section{RESULTS}

Primary antibody response.-No adults had detectable immunoglobulin-G antibody titers to any antigen before inoculation. However, at the first sampling interval after inoculation all treated females had measurable titers, whereas negative control females remained seronegative throughout the trial (Fig. 1). Titers rose rapidly among inoculated females within 2-5 weeks postinoculation and reached levels between 1:6,400 (diphtheria), and 1:51,200 (keyhole limpet hemocyanin, and bovine thyroglobulin) within 2 months. Titers then declined slightly and plateaued. Generally, all females responded with nearly equal intensity to exposure to a specific antigen (confidence intervals were $<1 \log$ unit). The exception was a single female inoculated with diphtheria-tetanus toxoid that, by accident, received only a partial dose (ca. $30 \mu \mathrm{g}$ ) of antigen. Its titer peaked at 1:1,600 (diphtheria) and 1:3,200 (tetanus), and remained low throughout the study. Combining tetanus toxoid and diphtheria antigens into a single inoculum had no apparent impact on the magnitude of the antibody response by females (Fig. 1).

Antibody titers persisted at high levels for 4.5-6.0 months. By 5-6 months, titers to tetanus and diphtheria toxoid antigens began to decline, whereas titers to the remaining antigens remained high. A booster produced a marked response, resulting in a two-five-fold rise in titer that persisted for 3-4 months. Titers for animals receiving no additional antigen continued to decline through this period (Fig. 1).

Reproduction had no apparent effect on the long-term titers of females. Reproductively active females had titer half lives of $138 \pm 23$ days, not different from that of females that did not produce offspring (140 \pm 47 days).

Inoculation also had no apparent effect on fecundity as $48 \%$ of females produced at least one litter. Mean litter size was 4.0 (range, 2-7). There were no adverse effects, as measured by deaths or incapacitating reactions, associated with inoculation.

Maternal antibody in offspring.-Maternal antibody in offspring of inoculated females was $1: 800-1: 12,800$ at the initial bleeding ( 2 weeks of age), peaked by week 3 , then decayed exponentially over time (Fig. 2). None of the offspring $(n=7)$ born to control females was seropositive. Minimal detectable titers (1:100) were reached between $7-11$ weeks after birth (Table 1). The length of time antibodies could be detected was correlated positively with titers of females. Offspring born to females with diphtheria toxoid antibodies had the shortest detection time, and 

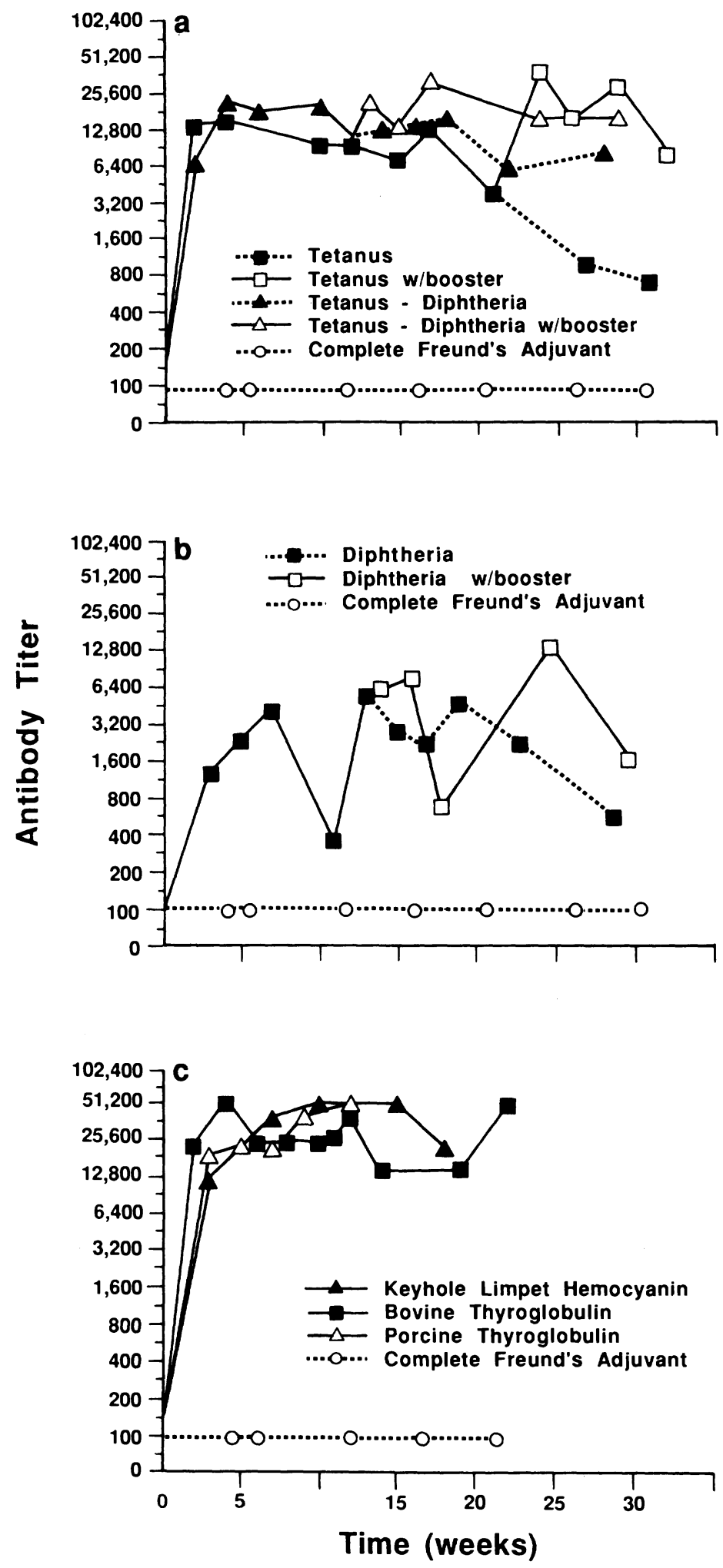

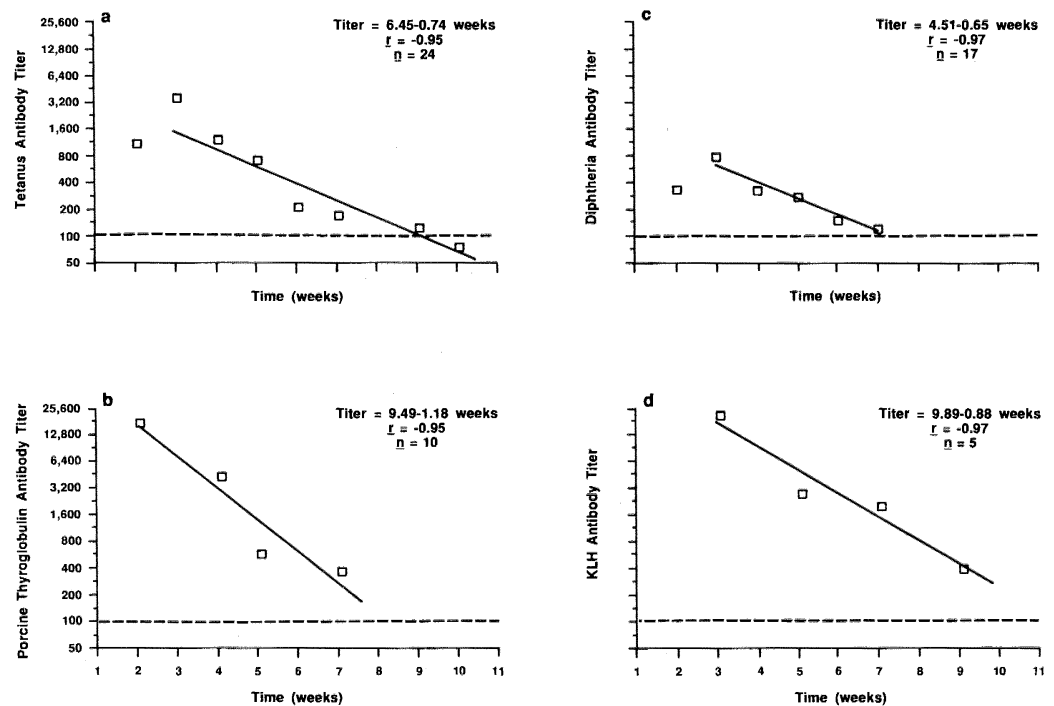

Fig. 2.-Decay of maternally derived antibodies in offspring of inoculated females for: a, tetanus toxoid; b, diphtheria toxoid; c, porcine thyroglobulin; and d, keyhole limpet hemocyanin. Regression lines are fit to data beginning with weaning at week 3 . The horizontal dotted lines represent the minimal detectable titers by enzyme-linked immunosorbent assay. Regression equations for titers are given in dilution units (titer $=$ $100 \times 2^{y}$, where $y$ is the dilution unit). Sample sizes are the numbers of offspring from litters used to calculate the mean titers.

offspring born to females with keyhole limpet hemocyanin antibodies had the longest detection time.

The minimal time that detectable maternal antibody was observed varied with maternal titer and, in some instances, was fairly short. However, antibodies could be detected in more than half the offspring at 10 weeks of age. Titers remained detectable in $>93.1 \%(n=130)$ of samples from offspring $\leq 6$ weeks of age (Fig. 3). After 6 weeks, $28.6 \%$ of the offspring were seronegative and they remained so throughout the remainder of the study. Offspring with the shortest histories of antibodies were from females that did not receive additional antigens with low $(<1: 3,000)$ tetanus or diphtheria antibody titers. All offspring born to females with high titers $(>1: 12,800)$ remained seropositive for $\geq 8$ weeks (Fig. 2). Antibodies were detected in two offspring 111 days old but beyond 12 weeks $<50 \%$ of the offspring had detectable titers.

Examination of antibody persistence, based on offspring weight (Fig. 3), leads us to suggest that maternal antibody is present in most voles until they reach nearly adult body weight. More than $90 \%$ (121 of 134) of the samples from offspring that weighed $<35 \mathrm{~g}$ had detectable levels of antibodies. Above this weight class the percentage of samples with antibodies declined to approximately $63 \%$. However, $15.2 \%$ of the voles did not reach this weight by 5 months of age.

Cross-reactivity of antibodies.-Porcine and bovine thyroglobulins are similar molecules and the potential exists for the antibodies formed against one antigen to cross-react with the other. In all instances $(n=20)$ of sera tested against homologous and heterologous antigens the ho-

FIG. 1.-Changes in antibody titers over time for female Microtus pennsylvanicus following inoculations with: a, tetanus toxoid only (squares), and tetanus and diphtheria toxoids (triangles); b, diphtheria toxoid; and c, keyhole limpet hemocyanin (closed triangles), bovine thyroglobulin (squares), and porcine thyroglobulin (open triangles). In a, and b, open symbols indicate individuals whose titers were enhanced with a second dose of antigen. 
TABLE 1.-Antibody dynamics in female Microtus pennsylvanicus and their offspring. All time variables are in weeks. Titers are inverses of dilutions. Data for offspring are the mean, and range of times that maternal antibodies could be detected. Sample sizes are the numbers of individuals tested for antibodies.

\begin{tabular}{lccrrr}
\hline \multicolumn{1}{c}{ Category } & \multicolumn{5}{c}{ Antigen } \\
\cline { 2 - 5 } & Tetanus & Diphtheria & Keyhole limpet & Bovine & Porcine \\
\hline Adults & & & & & \\
Time to peak titer & 5 & 6 & 10 & 4 & 9 \\
Time to half life & 18 & 18 & 18 & 15 & 51,200 \\
Maximum titer & 16,625 & 6,428 & 51,200 & 51,200 & 5 \\
Sample size & 15 & 8 & 5 & & \\
Offspring & & & 11.2 & & 8.0 \\
Mean detectable time & 8.7 & 7.0 & $11-11$ & 0.8 \\
Range of detectable time & $1-16$ & $5-14$ & 1.6 & 10 \\
Half life of antibody & 1.9 & 1.0 & 5 & \\
Sample size & 24 & 17 & & \\
\hline 'Titer was maximal at the termination of the experiment. Half life was $>12$ weeks. &
\end{tabular}

mologous reaction produced titers at least three-fold higher than the heterologous antigen. Thus, titering with enzyme-linked immunosorbent assays permitted a distinction between antibodies directed against even closely related antigens.

Screening naive wild voles.-Only 1 of 26 serum samples from wild-caught voles reacted with any of the antigens tested ( $n=130$ tests). This individual had a titer of 1:200 directed against tetanus-toxoid antigen, but was seronegative against the other four antigens. None of the other individuals had detectable titers $(1: 100)$ against this or other antigens. Based on the statistical criteria used to define a seropositive sample ( $\geq 3 S D>\bar{X}$ of negative controls), no more than one false-positive result in $98.7 \%$ of such series is expected, if samples are considered trials of a binomial-random variable. Thus, wild-caught, uninoculated animals appear to circulate antibodies to these or similar antigens at sufficiently low frequencies that misidentification because of natural exposure or cross-reactions is low. In addition, they demonstrate the specificity of enzyme-linked immunosorbent assays for detecting introduced, exotic antigens.

\section{Discussion}

The passive transfer of maternal antibody directed against exotic antigens (exotic-antigen technique) appears to be a feasible method for determining maternal-offspring relationships in rodents. The antibody responses produced in females are long-lasting, can be enhanced, are unaffected by parity, and are sufficiently specific to distinguish between closely related antigens. Many antigens are commercially available for marking females, and they may be given in combination without an apparent impact on the duration or specificity of the primary antibody response. Antibodies are transferred during nursing, and persist in offspring for sufficient intervals to be detected by most trapping protocols. In addition, the potential for false-positive readings among uninoculated wild animals appears to be low.

The transfer of maternal antibodies, and the passive immunization of offspring, is a general characteristic of mammals (Beer and Billingham, 1976; Brambell, 1970). Differences in timing and mode of transfer exist but appear to have little impact on the duration of antibody persistence in offspring. In primates, lagomorphs, and guinea pigs (Cavia sp.), antibody transfer occurs through the yolk sac and vitelline circulation, and is mediated by Fc (crystalizable fragment) receptors (Brambell, 1970; Kraehenbuhl and Campiche, 1969). No antibody is transferred after birth but it can be detected for $\leq 2.5$ months in offspring.

In ungulates, maternal antibody is sequestered from the mother's serum before birth, and transferred in colostrum during the initial $24 \mathrm{~h}$ after birth (Beer and Billingham, 1976; Kraehenbuhl and Campiche, 1969). Maternal antibodies can be detected in some instances for 3 months (Brambell, 1970). 

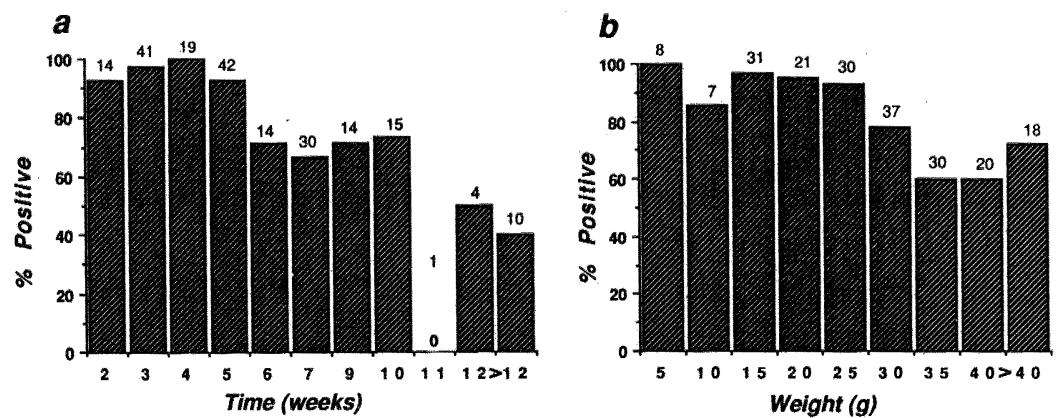

Fig. 3. - The proportion of samples from offspring with maternally derived antibodies by: a, age; and b, weight. Numbers above bars are sample sizes.

In contrast, infant rats (Rattus norvegicus), mice (Mus musculus), hedgehogs (Erinaceus europaeus), domestic cats, and dogs receive maternal antibodies both transplacentally and during lactation (Beer and Billingham, 1976; Morris, 1959, 1961), with most transferred after birth. In these species, maximal antibody titers are reached at or near weaning; titers then decay exponentially over time. In $R$. norvegicus, immunoglobulin-G absorption occurs in the proximal small intestine, and is mediated by $\mathrm{Fc}_{\mathrm{c}}$ receptors in this region. Changes in the absorptive abilities near weaning terminate the acquisition of antibodies (Abrahamson et al., 1979; Morris, 1975). Thus, antibody titers begin to decrease in the offspring because of physiological changes in the infant and not because the mother's antibody stores are depleted. Maternally transferred antibody remains detectable for >6-10 weeks in these species (Arango-Jaramillo et al., 1988; Brambell, 1970; Reuman et al., 1983; Williams et al., 1974; Zhang et al., 1988).

In this study, Microtus pennsylvanicus appears to follow a passive immunization pattern like that of Rattus, Mus, Erinaceus, Felis, and Canis. Antibody levels peak close to the maternal antibody titer at 3 weeks (weaning) then decline exponentially, persisting 7-11 weeks. In practical terms, sampling on a biweekly schedule should provide two or three trapping periods when $>90 \%$ of young animals could be identified by this method (Fig. 3). The maximal duration of maternal antibody persistence in offspring raises the possibility that early breeding offspring might transmit passively derived antibodies from their mothers to their own offspring, effectively marking more than one generation. However, we expect this will be unlikely. Even if offspring of inoculated female voles breed at 6 weeks of age, their offspring would not be weaned until the young females were 12 weeks old. During this time the passively acquired antibodies are catabolized, and titers in the young mothers would be low or undetectable (Fig. 3, Table 1). Titers in their offspring would be two-four-fold lower (Fig. 2), and probably unmeasurable. Thus, the exotic antigen technique is unlikely to identify multiple generations in a lineage using a single inoculation. This is a significant advantage because it permits assignment of maternity to a single female rather than to a cohort of related females.

Maternity can be established unequivocally only for species such as Cavia in which antibody transfer occurs before birth, and can be inferred strongly for ungulates, in which antibody transfer occurs during the first $24 \mathrm{~h}$ of life. As with the radionuclide-marker technique, the presence of antibodies in species such as meadow voles indicates that infants have nursed from a particular female. As such, maternity is inferred from nursing patterns and knowledge of the social behavior of the species (Tamarin et al., 1983). Consequently, the exotic-antigen technique also could be used in species that transmit maternal antibodies during nursing to detect evidence for cooperative brood care among social females (Hoogland et al., 1989). Finding antibodies to multiple antigens in individuals when females are inoculated with single antigens would indicate the offspring nursed from more than one female.

The persistence of the primary antibody response in females means that it is unnecessary to resample repeatedly population members. As such, the exotic-antigen technique would be useful 
with species difficult to recapture. The technique also could be used to estimate a lower limit for the proportion of breeding adult females not recaptured in small-mammal populations, and currently are considered dead in studies of population dynamics (Nichols, 1986). Identifying their offspring in the population would confirm female survival without retrapping.

The potential to enhance the primary antibody response is useful as maternal antibody appears to be undetectable by 6 weeks in offspring born to females with low titers (Fig. 3), but persists for $\geq 8$ weeks in females with high titers. The anamnestic response (Fig. 1) might have been prolonged even further by mixing the antigen with incomplete Freund's adjuvant, to slow the release of antigen from the depot (Herbert, 1978).

The ability to distinguish between antibodies to closely related antigens using enzyme-linked immunosorbent assays is particularly useful because it increases the numbers of antigens available for marking individual females. For example, we also developed assays for: turkey- and chickenegg albumins, horseshoe crab (Limulus polyphemus) hemocyanin, and horse myoglobin. When pairs of the related antigens (egg albumins and hemocyanins) were assayed comparatively, differentiable antibody titers also existed making it possible to identify the specific antigen used.

In addition to commercially available proteins, various other agents could be used to elicit immune responses. Hapten-like molecules, cloned viral antigens, synthetic peptides, and red blood cells from various species are potential candidates. General characteristics of good antigens are discussed by Herbert (1978). A major advantage of all these agents is their safety for the animals, the user, and the environment. Most have been used in laboratory Mus and Rattus to study immunological responses with no apparent negative effects for the inoculated animals (Herbert, 1978). Except for using standard laboratory precautions, we are unaware of any special protection necessary for users of the technique. Because the exotic-antigen technique immunizes inoculated animals with nontoxic, nonreplicating, antigens, risks to the environment also are reduced. In theory, attenuated live agents (e.g., viruses) could be used as antigens, with the advantage that offspring could be exposed to the antigen as well, causing them to produce their own primary antibody responses. However, the introduction of novel, live agents into the environment has significant ethical considerations that would seem to preclude their use.

The specificity of the enzyme-linked immunosorbent assay also reduces the likelihood of misidentifying wild animals because of cross-reactions to other antigens. The number of false positives among wild-caught voles was within the expected number of errors based on the statistical definition of a positive reaction. From a preliminary study with woodchucks (Marmota monax), we saw no evidence of cross-reacting antibodies in uninoculated animals $(n=40)$, and a rapid, persistent primary response in inoculated females. However, this condition must be verified empirically for each population studied before initiating inoculations.

The transfer of maternal antibody to nursing offspring appears to be a feasible method for identifying maternal-offspring relationships in mammals. Enzyme-linked immunosorbent assays provide a quick, reliable, highly specific technique for detecting antibodies, and requires a small volume of serum (ca. $2 \mu \mathrm{l} /$ antigen), critical for species for which large blood samples could affect survival. One drawback to this assay system is that it requires that each serum sample be tested against each antigen separately. We currently are attempting to blot combinations of antigens onto nitrocellulose filter strips so that serological reactions against multiple antigens can be visualized in a single test. The logistical advantages of identifying maternal-offspring relationships by immunodiagnostic techniques should make the exotic-antigen technique a widely applicable methodology to study mammalian kinship under natural conditions.

\section{ACKNOWLEDGMENTS}

We thank A. Scott, R. A. Arthur, N. R. Rose, G. W. Korch, and E. Talor for assistance with technical aspects of this study. R. K. Swihart kindly permitted us to cite data from his study with woodchucks. R. H. Tamarin and two anonymous reviewers read and commented on earlier drafts of this paper. Partial support was provided by the Sloan Foundation, a Public Health Services Biomedical Research Support Grant, and Department of Defense contract DAMD17-87-C-7101 to GEG and JEC. This paper does not reflect the 
position of the Department of Defense or the Department of the Army. All animals were handled according to National Institutes of Health guidelines for the care and use of laboratory animals.

\section{Literature Cited}

Abrahamson, D. R., A. Powers, and R. Rodewald. 1979. Intestinal absorption of immune complexes by neonatal rats: a route of antigen transfer from mother to young. Science, 206:567-569.

Arango-Jaramillo, S., C. L. Wisseman, JR., and A. F. AzAD. 1988. Newborn rats in the murine typhus enzootic infection cycle: studies on transplacental infection and passively acquired maternal antirickettsial antibodies. American Journal of Tropical Medicine and Hygiene, 39:391-397.

Beacham, T. D. 1979. Dispersal tendency and duration of life of littermates during population fluctuations of the vole Microtus townsendii. Oecologia (Berlin), 42:1-10.

Beer, A. E., and R. E. Billingham. 1976. The immunobiology of mammalian reproduction. Prentice-Hall Inc., Englewood Cliffs, New Jersey, 240 pp.

Brambell, F. W. R. 1970. The transmission of passive immunity from mother to young. Frontiers of Biology, North-Holland Publishing Company, Amsterdam, 18:1-385.

Chesser, R. K. 1983. Genetic variability within and among populations of the black-tailed prairie dog. Evolution, 37:320-331.

Childs, J. E., G. E. Glass, G. W. Korch, and J. E. LEDuC. 1987. Prospective seroepidemiology of hantaviruses and population dynamics of small mammal communities of Baltimore, Maryland. American Journal of Tropical Medicine and $\mathrm{Hy}$ giene, 37:648-662.

Drummond, J. E., K. V. Shah, AND A. D. Donnenberg. 1985. Cell mediated immune responses to $\mathrm{BK}$ virus in normal individuals. Journal of Medical Virology, 17:237-248.

Goundie, T. R., AND S. H. Vessey. 1986. Survival and dispersal of young white-footed mice born in nest boxes. Journal of Mammalogy, 67:53-60.

Herbert, W. J. 1978. Mineral-oil adjuvants and the immunization of laboratory animals. Pp. A3.1A3.15, in Handbook of experimental immunology (D. M. Weir, ed.). Blackwell Scientific Publications, Oxford, England, 384 pp.

Hoogland, J. L., R. H. Tamarin, and C. K. Levy. 1989. Communal nursing in prairie dogs. Behavioral Ecology and Sociobiology, 24:91-95.

JoNes, W. T. 1987. Dispersal patterns in kangaroo rats Dipodomys spectabilis. Pp. 119-127, in Mammalian dispersal patterns: the effects of social structure on population genetics (B. D. Chepko-Sade and Z. T. Halpin, eds.). The University of Chicago Press, Chicago, 342 pp.

KLEIN, J. 1982. Immunology: the science of selfnonself discrimination. John Wiley \& Sons Inc., New York, $687 \mathrm{pp}$.

Kraehenbuhl, J. P., and M. A. Campiche. 1969. Early stages of intestinal absorption of specific antibodies in the newborn: an ultrastructural, cyto- chemical, and immunological study in the pig, rat, and rabbit. Journal of Cell Biology, 42:345-365.

LeBoeuf, B. J., AND J. ReITER. 1988. Lifetime reproductive success in northern elephant seals. Pp. 344-362, in Reproductive success (T. H. CluttonBrock, ed.). The University of Chicago Press, Chicago, $538 \mathrm{pp}$.

ZomNICKI, A. 1988. Population ecology of individuals. Princeton University Press, Princeton, New Jersey, $233 \mathrm{pp}$.

Mangel, M., and C. W. Clark. 1988. Dynamic modeling in behavioral ecology. Princeton University Press, Princeton, New Jersey, 308 pp.

MorRIS, B. 1959. Transmission of passive immunity in an insectivore. Nature, 184:1151.

- 1961. The transmission of anti-salmonella agglutinins from the mother to the young in Erinaceus europaea, with some observations on the active immunization of suckling hedgehogs. Proceedings of the Royal Society of London, Series B, 154:369-376.

- 1975. The transmission of ${ }^{125}$ I-labelled immunoglobulin $\mathrm{G}$ by proximal and distal regions of the small intestine of 16-day-old rats. Journal of Physiology, 245:249-259.

NiCHOLS, J. D. 1986. On the use of enumeration estimators for interspecific comparisons, with comments on a 'trappability' estimator. Journal of Mammalogy, 67:590-593.

PACKER, C., ET AL. 1988. Reproductive success of lions. Pp. 363-383, in Reproductive success (T. H. Clutton-Brock, ed.). The University of Chicago Press, Chicago, 538 pp.

Reuman, P. D., C. M. Paganini, E. M. Ayoub, and P. A. SMall. 1983. Maternal-infant transfer of influenza-specific immunity in the mouse. Journal of Immunology, 130:932-936.

RongSTAD, O. 1965. Calcium-45 labeling of mammals for use in population studies. Health Physics, 11:1543-1556.

ScotT, M. P., AND T. N. TAN. 1985. A radiotracer technique for the determination of male mating success in natural populations. Behavioral Ecology and Sociobiology, 17:29-33.

Sheridan, M., aNd R. H. TAMarin. 1986. Kinships in a natural meadow vole population. Behavioral Ecology and Sociobiology, 19:207-211.

Smith, H. R., and R. J. Sloan. 1988. Estimated population size in a wild population of Peromyscus leucopus. Journal of Mammalogy, 69:176-177.

Tamarin, R. H., M. Sheridan, and C. K. Levy. 1983. Determining matrilineal kinship in natural populations of rodents using radionuclides. Canadian Journal of Zoology, 61:271-274.

VolleR, A., AND D. BIDWELl. 1986. Enzyme-linked immunosorbent assay. Pp. 99-109, in Manual of clinical laboratory immunology (N. R. Rose, H. Friedman, and J. L. Fahey, eds.). American So- 
ciety of Microbiology, Washington, D.C., 1,002 pp

Williams, J. E., J. D. Marshall, D. M. Schaberg, R. F. Huntley, D. N. Harrison, and D. C. Cavanaugh. 1974. Antibody and resistance to infection with Yersina pestis in the progeny of immunized rats. Journal of Infectious Diseases (suppl.), 129:72-77.

WolfF, J., and D. Holleman. 1978. Use of radio- isotope labels to establish genetic relationships in free-ranging small mammals. Journal of Mammalogy, 59:859-860.

Zhang, X. K., I. Takashima, and N. Hashimoto. 1988. Role of maternal antibody in protection from hemorrhagic fever with renal syndrome virus infection in rats. Archives of Virology, 103:253265.

Submitted 13 April 1989. Accepted 29 August 1989. 